\title{
Problemas de Comunicação da Informação Científica
}

\author{
EDSON NERY DA FONSECA \\ Professor da Universidade de Brasília. \\ Chefe do Departamento de Biblioteconomia \\ da UnB
}

\begin{abstract}
SINOPSE: Distinção entre comunicação para as massas e comunicação entre cientistas. Formação de bibliotecários especializados que sejam especialistas em informação cientifica. Importância, na pesquisa científica, da bibliografia, encarada como conhecimento e referenciação de textos. Motivações econômica e especulativa da pesquisa bibliográfica. A explosão bibliográfica e o bibliotecário do futuro, segundo Ortega y Gasset e Abraham Moles. Os conceltos de entropia e negentropia na teoria da informação. O documentalista como Demônio de Maxwell. Utilização das normas de comunicação científica pelos autores e editóres. O livro, a revista e o relatório como veículos de comunicação entre cientistas. Soluções prospectivas para o problema da informação científica.
\end{abstract}

Discutiu-se recentemente, na Universidade de Brasília, a pertinência da expressão "Informação Científica" no título de uma de suas Faculdades - a de Biblioteconomia - que é, por sinal, a mais citada nos esquemas do Plano Orientador da mesma Universidade. Pela primeira vez no Brasil, o ensino de Biblioteconomia foi atribuído a uma Faculdade, que deveria receber concluintes de qualquer curso básico - de Ciências Biológicas, Exatas e Humanas, bem como de Letras e de Artes para formar bibliotecários especializados.

Dêstes, na verdade, é que o Brasil e a nossa época necessitam; e não dos bacharéis em biblioteconomia supostamente enciclopédicos: os preparados pelas universidades federais, de acôrdo com um currículo mínimo já obsoleto.

A expressão - que aparece em várias publicações de língua inglêsa, na qual consagrou-se por duas conferências internacionais: a Royal Society Scientific Information Conference (Londres, 1948) e a International Conference on Scientific Information (Washington, 1958) - foi acrescentada ao título da 
Faculdade de Biblioteconomia prevista no Plano Orientador da UnB, não por capricho, mas para definir o que deve ser o bibliotecário especializado: um especialista em informação científica.

A idéia de colocar-se um curso de Biblioteconomia com essa orientação nas chamadas faculdades ou escolas de comunicações resulta de uma confusão semântica da comunicação para as massas - cujos veículos são a imprensa, o rádio e a televisão - com a comunicação entre cientistas, que se faz por meio da revista, do relatório não impresso e da comunicação em congressos.

Nenhuma universidade brasileira mostrou-se até agora mais sensível ao problema da informação científica do que a Universidade Federal de Minas Gerais. Ainda recentemente essa Universidade confirmava seu interêsse pelo assunto, incluindo no programa de um curso de Metodologia da Pesquisa Científica um ponto sôbre a importância da bibliografia. Isso de pesquisa bibliográfica, entretanto, não é tema do qual se possa dizer que venha sendo levado a sério pelas universidades brasileiras.

Neste particular, aliás, as universidades só fazem seguir uma tradição cultural de improvisações e devaneios impressionistas: inimiga, portanto, de qualquer esfôrço honesto e sério de pesquisa. O trabalho bibliográfico é encarado com desdém pela maior parte dos nossos pesquisadores. Um Plínio Ayrosa e um Alfredo do Vale Cabral elaborando bibliografias da língua tupi-guarani ( $\left.\begin{array}{lll}1 & \text { e } & 4\end{array}\right)$ *, um Herbert Baldus a de Etnologia (2), um Alfeu Diniz Gonçalves a de ciências geológicas (10) são exceções que só fazem confirmar a regra.

Que a Universidade Federal de Minas Gerais está entre as exceções nós já sabíamos por alguns indícios significativos, como, por exemplo, a publicação, na sua revista, dos artigos do professor Borisas Cimbleris (6) e do bibliotecário holandês L. J. van der Wolk. (26) Somado a tais indícios, o recente curso de Metodologia da Pesquisa Científica representa a consagração do que já em 1939 afirmava o mestre português Fidelino de Figueirêdo, pioneiro na luta pela introdução da bibliografia em nossos cursos universitários: "O muito que o trabalho do saber comporta de inspiração individual não dispensa nem ofusca o seu caráter de colaboração numa grande gesta, em que disciplinarmente e organizadamente se empenham os

* Os números indicam as referências bibliográficas alfabèticamente ordenadas no fim do texto. 
espíritos melhores de tôda a parte". Pois "quem não quiser descobrir de nôvo o mar Mediterrâneo - concluía Fidelino de Figueirêdo - deve pôr-se a par do que anteriormente se realizou na tarefa ingente de uma mais aproximativa compreensão do homem, da terra e do universo." (7, p. 42).

Aí está, nestas palavras de Fidelino de Figueirêdo, perfeitamente definida a importância da bibliografia na pesquisa científica: colocando o pesquisador a par do que outros realizaram antes dêle, a bibliografia evita repetições ou duplicações como as que Darwin e outros naturalistas realizaram por desconhecerem o artigo no qual Mendel falava de suas experiências com vegetais hibridos (21, t. III, v. 1, p. 552-554).

Se em meados do século XIX, quando Mendel publicou o seu artigo, já era possivel que isso acontecesse, pode-se perfeitamente imaginar o que ocorre em nossos dias, com a explosão científica e tecnológica da qual a chamada explosão bibliográfica é apenas uma conseqüência.

Pois "tudo no mundo existe para acabar em livro", como dizia Mallarmé, sendo interessante atentar para o fato de que, antes de acabar em livro, as idéias novas introduzidas pela ciência e pela tecnologia passam por diversos estágios, como o dos "pre-prints" para discussão em conclaves, o dos relatórios para distribuição no micro-meio científico e o dos artigos em publicações periódicas.

"A natureza - escreve êsse grande filósofo da ciência que é o estruturalista francês Michel Foucault - é, em si mesma, um tecido ininterrupto de palavras e de marcas, de narrativas e de caracteres, de discursos e de formas. Quando se tem de fazer a história de um animal, inútil e impossivel é escolher entre o ofício de naturalista e o de compilador: o que é preciso é recolher, numa única e mesma forma do saber, tudo o que foi visto e ouvido, tudo o que foi contado pela natureza ou pelos homens, pela linguagem do mundo, das tradições ou dos poetas. Conhecer um animal ou uma planta, ou uma coisa qualquer da terra, é recolher tôda a espêssa camada dos signos que foram colocados nelas ou sôbre elas" (8, p. 63-64).

Não nos antecipemos, porém. Vejamos como a bibliografia se insere na pesquisa científica, o que nos obriga a uma incursão sôbre o próprio fenômeno da criação de idéias novas. Ninguém analisou melhor êsse fenômeno do que Abraham A. Moles, em sua obra Sociodynamique de la Culture. (14). 
Segundo Moles, a criação de idéias novas se escalona em duas fases, por êle denominadas "temps de conception" e "temps d'emballage". A fase de concepção pode ser escalonada em fase de gestação ("temps de gestation") e fase de formulação explícita ("temps de formulation explicite"). A gestação das idéias novas não ocorre no vácuo. Todo criador é o produto de um campo cultural implantado no seu espírito. As idéias novas, por sua vez, são apenas elos de uma cadeia. Como observou Henry Lefebvre, se pudéssemos reconstituir as cadeias das citações, perceberiamos quão raramente se introduz nos textos uma idéia nova: encontraríamos onde determinada idéia foi introduzida, por quem, aquilo em que ela se tornou, como se metamorfoseou, onde morreu, onde está seu túmulo" (12, p. 182).

Com efeito, a criatividade não é mais do que uma aptidão especial de certos espíritos para reagrupar elementos nunca antes reunidos, sendo muito mais pertinente falarmos, em têrmos puramente humanos, de recriação, porque, em sentido absoluto, só Deus pode criar. Falando em recente mesa-redonda, promovida pela revista Le Nouveau Planète, O professor Jean Cazeneuve afirmou: "Les grandes découvertes sont généralement des mises en relation. Inventer, c'est trouver un nouveau rapport" $(18$, p. 16$)$.

Por isso, na própria fase ou tempo de gestação, há que distinguir, como salienta Abraham Moles, um "tempo de documentação e de informação". Tempo de documentação e de informação que ocupa geralmente um têrço ou mesmo a metade do tempo de gestação. As emprêsas industriais, os grandes serviços de pesquisa, os comitês de redação das revistas sabem calcular, algumas vêzes de modo relativamente exato, quanto dura o tempo de gestação em alguns setores particulares do mundo cultural. Êles sabem, por exemplo, que para colocar um engenheiro a par de determinada questão é necessário prever alguns meses de documentação. Bright Wilson - autor de uma das obras fundamentais sôbre a pesquisa cientifica - já havia escrito que "six hours in the library may save six months in the laboratory" (25, p. 10). Em sintese magistral, Anísio Teixeira definiu a pesquisa como "a utilização do conhecimento existente para a descoberta de novos conhecimentos" (22, p. 30).

"Todos os estudos sôbre o processo da criatividade continua Moles - concordam em distinguir certa latência entre - momento em que uma questão muito vaga se coloca ou é colocada perante um pesquisador e o momento em que êle 
se torna capaz de a formular em têrmos de problema a resolver, isto é, momento em que êle seleciona, no campo das possibilidades, um certo número de pontos particulares que representam uma diligência ou uma estratégia do espírito" (14, p. 83-84). E aí que se insere o tempo de documentação e de informação.

Como pode o pesquisador documentar-se e informar-se diante de uma produção bibliográfica tão numerosa que ultrapassa os limites de seu tempo e de sua capacidade de assimilação? Sabe-se, por exemplo, que em cada quarto de hora publica-se no mundo um trabalho nôvo no campo da Química. Cada químico deveria ler, portanto, quatro trabalhos por hora. Se o fizesse, entretanto, mesmo restringindo-se a trabalhos relevantes, deixaria de ter tempo para as pesquisas.

É preciso, portanto - é urgente e essencial - que alguns químicos se dediquem exclusivamente à leitura do que se publica no campo da Química, selecionando e resumindo os trabalhos relevantes. Estarão êles sempre em dia quanto aos progressos obtidos no campo de sua especialização e saberão usar, para difusão dêsses progressos, os meios mais adequado. Chamaremos a êsses químicos, que renunciaram às pesquisas para se colocarem a serviço dos pesquisadores, de bibliotecários especializados em Química ou de Documentalistas da Química.

Para isso é que terão de ser criados cursos de Biblioteconomia em nível de pós-graduação e não para tornar os bacharéis em Biblioteconomia ainda mais alienados, como parece ser o destino de certos cursos nos quais se aprendem técnicas sofisticadas de armazenagem e recuperação da informação, sem que a êsse aprendizado corresponda o domínio de uma área do saber. Sem que ao processo corresponda uma substância.

Sòmente assim - isto é: sòmente elevando a Biblioteconomia a um nivel de pós-graduação que tenha como suporte o domínio sistemático de uma determinada área do saber é que poderemos entender a profecia de Ortega y Gasset, quando se referia "ao futuro bibliotecário como um filtro que Se interpõe entre a torrente de livros e o homem" (15, p. 43). Escritas em 1935 e proferidas em Madrid, na abertura de um Congresso Internacional de Bibliotecários, as palavras do notável ensaísta espanhol são ainda hoje de impressionante atualidade.

A explosão bibliográfica - fenômeno que Ortega foi 0 primeiro a analisar, de um ângulo ao mesmo tempo histórico e 
prospectivo - é hoje comparada à entropia, cujo conceito passou da termodinâmica para a teoria da informação. Em termodinâmica a entropia é, como se sabe, a degradação progressiva da energia. Em teoria da informação, a entropia consiste na degradação progressiva da comunicação, pelo aumento de elementos redundantes que tornam a informação menos rica de novidades. Assim, o máximo de comunicação corresponde ao mínimo de informação.

Também da termodinâmica veio para a teoria da informação o conceito de entropia, baseado na câmara inventada por James Maxwell. Dividida em dois compartimentos, essa câmara deixava passar para o compartimento da direita apenas as moléculas de gás de movimento rápido, graças a uma porta deslizante e sem atrito, que era fechada para as moléculas de movimento lento por um porteiro hipotético: o demônio de Maxwell.

Se o problema da documentação é, como assinala Abraham Moles, o de fornecer um mínimo de informação possivel ao pesquisador, com a condição de que êsse mínimo seja estritamente relevante, o documentalista age como o demônio de Maxwell, aumentando o grau de ordem, diminuindo a entropia e violando, portanto, o segundo princípio da termodinâmica. "Para que o demônio de Maxwell possa agir - acrescenta Moles - será necessário obter de cada molécula uma informação total e que o esfôrço dêle exigido seja igual à diminuição da entropia que possa introduzir" $(19$, p. 136).

$\mathrm{Na}$ pesquisa bibliográfica, entretanto, a diminuição da entropia não depende apenas do demônio de Maxwell, mesmo que êle tenha as condições ideais a que já nos referimos, isto é, conhecimento de determinada área do saber e das técnicas de seleção e resumo, armazenagem e recuperação da informação. As próprias técnicas de embalagem ou de corporificação material da informação têm de ser reformuladas para que o processamento de sua difusão seja eficaz.

$\mathrm{Na}$ verdade, a entropia ou desordem que se observa na comunicação entre cientistas não resulta apenas do número excessivo de meios, mas da falta de uma normalização e de uma padronização adequada dêsses meios. Os canais da comunicação científica estão bloqueados por veículos que, sôbre serem excessivos em número, continuam a ser produzidos sem nenhum respeito às recomendações internacionais e às normas nacionais que regulam a matéria.

Ao anunciar profèticamente a automação dos serviços bibliográficos - quando escreveu, em 1935, ser necessário 
"crear una nueva técnica bibliográfica de un automatismo riguroso" (15, p. 41) - Ortega y Gasset percebeu, com admirável lucidez, que essa automação implica na própria racionalização e regulamentação dos meios de comunicação cultural. Aos que se insurgiam contra essa racionalização e essa regulamentação em nome de uma liberdade de criação mal interpretada, Ortega respondeu que ela nada tem a ver com o tema da liberdade, "como no tiene que ver con él la necesidad que se ha impuesto de reglamentar la circulación en las grandes urbes" (15, p. 42).

A comparação é perfeita: assim como não é admissível nem legal - neste caso, o direito positivo apenas legaliza 0 bom senso - que uma pessoa dirija veículos sem conhecer as leis do trânsito, também não se deve admitir que os canais da comunicação sejam tumultuados e bloqueados por informações transmitidas de acôrdo com os caprichos pessoais dos autores, as tradições obsoletas dos editôres e até com as limitações dos estabelecimentos gráficos.

Assim como os motoristas devem conhecer as leis do trânsito e as viaturas devem possuir certos equipamentos de segurança, os autores e editôres têm obrigação de conhecer as normas de comunicação científica e os veículos dessa comunicação devem ser normalizados para que as informações nêles contidas cheguem mais ràpidamente ao conhecimento dos interessados.

Na própria fase de concepção de idéias novas, se o criador não se submete às normas, corre o risco de fazer-se ininteligível na formulação explicita do que deseja comunicar. Não é outra coisa o que o Guia para a redação de artigos científicos destinados à publicação procura evitar, quando estabelece que as memórias científicas devem ser de tal modo redigidas que um pesquisador qualificado possa, a partir das indicações fornecidas, (a) reproduzir a experiência e obter os resultados descritos com a mesma precisão e sem ultrapassar a margem de erros especificada pelo autor, ou (b) repetir as observações, os cálculos e as deduções teóricas do autor e julgar suas conclusões $(24$, p. 6$)$.

Rejeitando as normas - que são conditio sine qua non da sobrevivência das publicações periódicas e da própria comunicação, além de representarem, como salientou o redatorchefe da revista Science, "uma disciplina essencial à honestidade científica" - alguns homens de ciência se refugiam nessa espécie de antipublicação que é o relatório. Em obra 
recente, Sidney Passman mostra como o problema dos relatórios científicos e técnicos se apresenta hoje nos Estados Unidos: as coleções das grandes bibliotecas não especializadas compreendem cêrca de um milhão de relatórios e êstes crescem no ritmo de muitas centenas de milhares por ano. (16)

Pela sua proliferação e pelo seu caráter de semi-publicação ou antipublicação, os relatórios se assemelham às patentes, com os graves perigos que apresentam para a universalidade do conhecimento científico. Com efeito, o relatório já foi definido como "a primeira versão não publicada de uma obra que não foi objeto de uma análise rigorosa nem está à disposição do mundo científico - uma obra que não merece, portanto, ser conservada nos arquivos da ciência". (16)

Ao criticar os relatórios não pretendo esconder o que há de criticável nas publicações periódicas como veículos de comunicação entre cientistas. Segundo os cálculos de Abraham Moles, o tempo niecessário para que as idéias novas, depois de explicitamente formuladas, cheguem ao conhecimento dos interessados, é da ordem de 8 a 10 meses: 1 mês para redação sob forma datilografada; 15 dias para a remessa a uma revista científica; 2 meses para seu exame pelo conselho técnicocientífico responsável pela publicação; 6 meses para impressão; 1 mês para difusão ou distribuição entre os assinantes. Há casos de delongas ainda maiores, como o de certas revistas anuais de Lingüística ou de Matemática, que saem sempre com um atraso de 2 ou 3 anos. Em síntese, as idéias novas se inserem no quadro sócio-cultural após um atraso da ordem de 8 meses a 2 anos (14, p. 209).

Daí o grande número de artigos sôbre a possibilidade de substituição das revistas científicas por outros meios de comunicação entre criadores e pesquisadores. A bibliografia sôbre o assunto foi comentada por Ralph Phelps e John Herlin, em trabalho publicado pela UNESCO (17), recomendando-se também, a propósito, a leitura do artigo de Pierre Bourgeois, "L'avenir du périodique scientifique." (3)

Inquéritos realizados entre pesquisadores de certas áreas - como a das ciências bio-médicas - revelam que a maior parte ainda prefere a comunicação individual por correspondência ou por debates em reuniões nacionais e internacionais (9). Alguns vão além, preferindo o chá no próprio laboratório ou a cerveja num café das vizinhanças. O grande cientista Oppenheimer chegou a dizer que o bate-papo nos laboratórios constitui metade do trabalho dos físicos: "gossips in labs make half of the work of the physicist" $(14$, p. 209). 
A comunicação por meio do livro não é menos problemática, sendo muito raro que as idéias divulgadas sob a forma do livro tradicional já não tenham aparecido nas revistas científicas, conforme um mecanismo bastante regular do trabalho intelectual. O atraso do livro tradicional na divulgação das idéias novas é da ordem de 2 a 3 anos: nìtidamente superior, portanto, ao dos periódicos (14, p. 210).

A produção de livros é mais complexa porque, enquanto uma revista pode subsistir com 200 assinaturas e 800 leitores, mais ou menos subvencionada por organismos oficiais, um livro não pode ser lançado sem a garantia de que pelo menos 500 leitores o adquiram, equivalendo a média das tiragens de 1.500 a 2.000 exemplares que devem ser "consumidos" de 4 a 5 anos. E claro que tais observações se aplicam ao chamado conjunto das línguas-vetores-de-cultura: a inglêsa $(40 \%$ das publicações mundiais), a italiana, a francesa, a espanhola e a alemã $(15 \%)$ e a russa $(10$ a $15 \%)(14$, p. 210$)$.

Mas, pelo fato mesmo de supor e impor maior número de exemplares, o livro atinge camadas mais amplas de consumidores, superando o micro-meio cultural em que circulam as revistas. Êle é muito mais distribuído pelas livrarias do que as revistas, nas quais, por outro lado, são noticiados e/ou analisados. Considere-se também que o livro renovou-se mais do que a revista, tanto no seu conteúdo - a "obra aberta" proposta por Umberto Eco ao micro-meio literário e artístico como na sua forma: a do livro de fôlhas sôltas.

Dou-me conta, agora, de que falei neste artigo mais de problemas do que de soluções. Já se disse que a diferença entre o cérebro humano e o artificial está no fato de que êste apresenta soluções enquanto só aquêle é capaz de colocar os problemas. Acontece que a única solução possível para o problema da comunicação entre os pesquisadores, em face da explosão bibliográfica, só pode ser dada pelos computadores. "É provável que venham a existir - escrevem Herman Kahn e Anthony Wiener no conhecido livro sôbre O Ano 2000 - mesas computadoras tipo consolo em todos os lares, ligadas a computadores de utilidade pública, permitindo a cada pesquisador consultar as centrais informativas interligadas por satélites." (11, p. 129). Idéia confirmada por Harry C. Campbell, na contribuição que escreveu para a obra coletiva editada pela UNESCO, Comunicação na era espacial (23, p. 143-155).

Tais cogitações me levam a concluir com uma recordação quase pessoal. Quando, em 1966, publiquei um manifesto - 
Ser ou não ser bibliotecário - no qual solicitava vox clamantis in deserto - que os bibliotecários procurassem aplicar ou pelo menos entender os novos processos de difusão do conhecimento, fui criticado pelo Sr. Carlos Victor Penna - argentino que dirige, em Paris, a Divisão de Bibliotecas da UNESCO para quem as soluções cibernéticas não têm sentido num continente como o latino-americano, onde o subdesenvolvimento exigiria a aplicação de técnicas mais modestas.

A suposição de que, em países subdesenvolvidos, as cogitações de natureza prospectiva ou futurológica têm um sentido meramente platônico baseia-se num simplismo sociológico e numa concepção estática do processo histórico. Em primeiro lugar, não existe apenas uma América Latina, mas várias, assim como não existe um só Brasil, mas vários Brasis, correspondendo a cada uma dessas Américas Latinas e dêsses Brasis necessidades diferentes e até contrastantes. Em segundo lugar, os processos tradicionais não são mais baratos do que os modernos, como ainda recentemente demonstrou Ralph $M$. Schoffner, no seu estudo "Economics of National Automation of Libraries" (20). Finalmente, existe o fenômeno que Kenneth Boulding, citado por Marshall McLuhan, chamou "limite de rutura": em qualquer meio ou estrutura, o sistema sùbitamente se transforma em outro ou atravessa um ponto irreversível em seu processo dinâmico (13, p. 56). Uma compreensão dinâmica dos meios de comunicação, tal como a demonstrada por McLuhan em Understanding Media, faz com que as nações novas dêem o salto que os processos mais atuais proporcionam, em vez de passarem pelos estágios intermediários dos paises mais antigos.

\section{REFERENCIAS BIBLIOGRAFICAS}

1. AYROSA, Plínio. Apontamentos para a bibliografia da lingua tupi-guarani. São Paulo, Faculdade de Filosofia, Ciências e Letras, 1954. 261 p.

2. BALDUS, Herbert. Bibliografia crítica da etnologia brasileira. São Paulo, Comissão do IV Centenário da Cidade de São Paulo, 1954. 859 p.

3. BOURGEOIS, Pierre. L'avenir du périodique scientifique. Libri (Copenhague) 7 (1): 71-76, 1956.

4. CABRAL, Alfredo do Vale. Bibliografia da lingua tupi-guarani também chamada língua geral do Brasil. Rio de Janeiro, Typographia Nacional, 1880. $81 \mathrm{p}$.

5. CAMPOS, Maria Apparecida Pourchet. A docência e a investigaçăo científica. São Paulo, Edição da Autora, 1962. 198p.

6. CIMBLERIS, Borisas. Gênese e busca da informação. Revista da Universidade Federal de Minas Gerais (Belo Horizonte) 14: 31-42, set. 1964. 
7. FIGUEIREDO, Fidelino de. Aristarchos. 2. ed. Rio de Janeiro, H. Antunes, 1941. $144 \mathrm{p}$.

8. FOUCAULT, Michel. As palavras e as coisas; uma arqueologia das ciências humanas. Trad. de António Ramos Rosa. Lisboa, Portugália, 1968. 502 p. (Colecção Problemas, 23)

9. GLASS, Bentley \& NORWOOD, Sharon H. How scientists actually learn of work important to them. In: International Conference on Scientific Information, Washington, 1958. Preprints of papers. Washington, National Academy of Sciences, National Research Council, 1958, Area I, p. $185-87$.

10. GONÇALVES, Alfeu Diniz. Bibliografia da geologia, mineralogia e paleontologia do Brasil. Rio de Janeiro, Officinas Typographicas do Serviço de Informações do Ministério da Agricultura, 1928. 205 p.

11. KAHN, Herman \& WIENER, Anthony J. O Ano 2000. 2. ed. São Paulo, Melhoramentos, 1969. 508 p.

12. LEFEBVRE, Henri. Posição: contra os tecnocratas. São Paulo, Editôra Documentos, 1969. 203 p. (Nova Crítica, v. 4)

13. McLUHAN, Marshall. Os meios de comunicação como extensões do homem. Trad. de Décio Pignatari. São Paulo, Cultrix, 1969. 407 p.

14. MOLES, Abraham A. Sociodynamique de la culture. Paris, Mouton, 1967. $342 \mathrm{p}$.

15. ORTEGA Y GASSET, José, El libro de las misiones, 5. ed. Buenos Aires, Espasa-Calpe Argentina, 1950. 147 p. (Colección Austral, 101)

16. PASSMAN, Sidney. Scientific and technological communication. Oxford, Pergamon Press, 1969. 161 p. Ver, sôbre êsse livro, a recensão de Herbert Coblans, Compte rendu d'ouvrage, Bulletin de l'Unesco à l'Intention des Bibliothèques (Paris) 24 (4): 238-240, jui./août, 1970.

17. PHELPS, Ralph \& HERLIN, John. Possibilidades de substituir la revista cientifica. Boletin de la Unesco para las Bibliotecas (Paris) 14 (2); 61-77, mar./abr. 1960.

18. PLANETE. Les mots sont des sons. Le Nouveau Planète (Paris) 17: 7-19, jui./août, 1970.

19. RUSSO, François. La fonction informationnelle dans le monde contemporain et la technique du traitement de l'information. In: Poirier, René, ed. Entrétiens en marge de la science nouvelle. Paris, Mouton, 1963, p. 129-137. O trecho citado é o da intervençáo de Abraham Moles na discussão da comunicação do padre François Russo, durante a reuniâo anual do Centro de Cultura Internacional de Cerizy-la-Salle (16-20 de julho de 1960)

20. SCHOFFNER, Ralph M. Economics of National Automation of Libraries. Library Trends (Urbana) 18 (4): 448-463, April 1970.

21. TATON, René, ed. Histoire générale des sciences. Paris, Presses Universitaires de France, 1961.

22. TEIXEIRA, Anísio \& SILVA, Maurício Rocha e. Diálogo sôbre a lógica do conhecimento. São Paulo, EDART, 1968. 116 p.

23. UNESCO. Comunicação na era espacial. Rio de Janeiro, Fundação Getúlio Vargas, 1969. $348 \mathrm{p}$. 
24. UNESCO. Guia para a redação de artigos científicos destinados à publicação. Traduzido por Lucy Gonçalves Fontes. Belo Horizonte, Escola de Biblioteconomia da UFMG, 1969. 18 p.

25. WILSON, E. Bright, Jr. An introduction to scientific research. New York, McGraw-Hill, 1952. 375 p.

26. WOLK, L. J. van der. As atividades do pesquisador de literatura cientifica. Tradução de João Baptista Villela. Revista da Universidade Federal de Minas Gerais (Belo Horizonte) 14: 43-51, set. 1964. 